\title{
Serous retinal detachment in patients with macular edema secondary to branch retinal vein occlusion
}

\author{
Descolamento seroso de retina em pacientes com edema macular secundário à oclusão de ramo \\ da veia retiniana
}

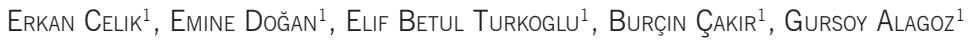

\begin{abstract}
Purpose: The aim of the present study was to evaluate visual acuity (VA) and centra macular thickness (CMT) to assess the influence of serous retinal detachment (SRD) in eyes with macular edema (ME) secondary to branch retinal vein occlusion (BRVO). Methods: Sixty-one eyes with BRVO from 61 patients with ME were analyzed and divided into two groups according to the spectral domain optical coherence tomography $(\mathrm{OCT})$ findings of SRD and cystoid macular edema (CME). All patients underwent complete ophthalmic examinations and OCT measurements (Cirrus, Carl Zeiss Meditec Inc, Dublin, CA). Patients with marked retinal hemorrhage, diabetic retinopathy, previous laser photocoagulation, and/or intravitreal injection were excluded.
\end{abstract}

Results: The mean age of included patients (37 males, 24 females) was $65.4 \pm$ 11.4 (53-77) years. There were 21 patients with SRD and 40 patients with CME. All of the 21 patients with SRD had CME. VA was significantly worse in the SRD group compared with the CME (non-SRD) group $(0.82 \pm 0.34 \log M A R$ vs $0.64 \pm$ $0.38 \log M A R ; P=0.005)$. Conversely, CMT was significantly greater in the SRD group than in the CME group $(465 \pm 115 \mu$ vs $387 \pm 85 \mu ; P=0.00004)$

Conclusion: SRD may be associated with decreased $V A$. The prognosis of patients with BRVO and SRD requires further investigation.

Keywords: Macular edema/etiology; Retinal detachment; Retinal vein occlusion/ complications; Optical coherence tomography; Visual acuity

\section{RESUMO}

Objetivo: O objetivo deste estudo foi investigar a acuidade visual (VA) e espessura macular central (CMT) para avaliar a influência do descolamento seroso da retina (SRD) em olhos com edema macular (ME) secundário a oclusão de ramo da veia da retina (BRVO).

Método: Sessenta e um olhos de 61 pacientes com oclusão de ramo da veia da retina e edema macular foram analisados e divididos em dois grupos, de acordo com os achados na a tomografia de coerência óptica por domínio espectral (OCT), de edema macular cistóide (CME) e descolamento seroso da retina. Todos os pacientes foram submetidos a exame oftalmológico completo e exame de tomografia de coerência óptica (Cirrus, Carl Zeiss Meditec Inc, Dublin, CA). Os pacientes com hemorragia acentuada da retina, retinopatia diabética, fotocoagulação a laser e/ou injeção intravitrea prévia foram excluídos.

Resultados: A idade média dos pacientes (37 homens, 24 mulheres) foi de 65,4 \pm 11,4 (53-77) anos. Havia 21 pacientes com SRD e 40 pacientes com edema macular cistóide. Todos os 21 pacientes com SRD também apresentaram edema macular cistóide. VA foi significativamente pior no grupo SRD do que no grupo edema macular cistóide (non-SRD) $(0,82 \pm 0,34$ vs 0,64 $\pm 0,38$ logMAR, $p=0,005)$. Por outro lado, a espessura macular central foi significativamente maior no grupo descolamento seroso da retina do que no grupo edema macular cistóide (465 $\pm 115 \mu$ vs $387 \pm 85 \mu, p=0,00004$ ).

Conclusão: Observou-se que o descolamento seroso da retina em si pode estar relacionado à diminuição de acuidade visual. Os prognósticos dos pacientes com oclusão de ramo da veia da retina e descolamento seroso da retina precisam ser adequadamente investigados.

Descritores: Edema macular/etiologia; Descolamento retiniano; Oclusão da veia retiniana/complicações; Tomografia de coerência óptica; Acuidade visual

\section{INTRODUCTION}

Branch retinal vein occlusion (BRVO) is the second most common retinal vascular disorder after diabetic retinopathy ${ }^{(1,2)}$. The typical presentation of BRVO is painless visual loss with flame-shaped retinal hemorrhages, cotton wool spots, and venous dilatation largely localized to the area drained by the occluded branch retinal vein ${ }^{(3)}$. In BRVO, increased intravascular pressure causes dysfunction of the endothelial blood-retinal barrier, resulting in increased vascular permeability, eventually leading to cystoid macular edema (CME). Increased interstitial oncotic pressure can also interrupt capillary perfusion and lead to ischemia ${ }^{(4,5)}$.

Macular edema is the most frequent cause of visual loss in patients with BRVO. Optical coherence tomography (OCT) studies have demonstrated that macular edema secondary to BRVO is frequently associated with CME, serous retinal detachment (SRD), and inner retinal thickening. SRD has been reported in 15\%-80\% of patients with $B R V O^{(6-8)}$. Although the mechanism underlying SRD has yet be fully elucidated, extensive leakage of fluid from capillaries in the ischemic retina affected by BRVO may lead to accumulation in the subretinal space and thus cause serous detachment ${ }^{(9)}$. Recently, studies have demonstrated that SRD and the loss of the photoreceptor layer leads to damage to the retinal pigment epithelium and neurosensory retina, contributing to the poor visual prognosis of BRVO ${ }^{(10-12)}$.

In the present study, we aimed to assess the effect of SRD on both visual acuity (VA) and central macular thickness (CMT) in patients with BRVO and macular edema.
Submitted for publication: April 14, 2015

Accepted for publication: October 20, 2015

Sakarya University Medical Education and Research Hospital, Sakarya, Turkey.
Funding: No specific financial support was available for this study.

Disclosure of potential conflicts of interest: None of the authors have any potential conflict of interest to disclose.

Corresponding author: Elif Betul Turkoglu. Akdeniz University Medical Education and Research Hospital. Antalya, 07100 - Turkey - E-mail: drelifbetul@gmail.com 


\section{METHODS}

We retrospectively reviewed the medical records of 61 eyes of 61 patients with macular edema secondary to BRVO, previously examined at the Department of Ophthalmology, Sakarya University Medical Education and Research Hospital, from February 2010 to January 2014. The present study was approved by the Institutional Review Board and adhered to the tenets of the Declaration of Helsinki.

Each patient had unilateral BRVO. All patients had CME and/or SRD ( $\geq 300 \mu$ on OCT). Patients were divided into two groups according to the spectral domain OCT findings of SRD and CME: patients with CME (Group 1) and patients with SRD (Group 2). All eyes in the SRD group had CME. CME was defined as hypo-reflective intraretinal cavities on OCT. On the other hand, SRD was defined as the presence of a non-reflective cavity with minimal shadowing of the underlying tissues due to subretinal fluid accumulation leading to the detachment of the neurosensory retina. The exclusion criteria included prior ocular surgery, diabetic retinopathy, previous laser photocoagulation and/or intravitreal injection, history of ocular inflammation, and marked retinal hemorrhage, including macular bleeding involving the subfoveal or intrafoveal spaces.

At initial examination, patients underwent complete ophthalmologic examinations, including VA, slit-lamp biomicroscopy, funduscopy, fundus color photography, fluorescein angiography, and spectral-domain OCT (Cirrus, Carl Zeiss Meditec Inc, Dublin, CA) analysis to measure the CMT and evaluate the presence or absence of CME/SRD. OCT images were obtained from each eye following pupil dilation by the same operator using the Macular Cube $512^{*} 128$ scan

Table 1. Clinical features of the CME and SRD groups

\begin{tabular}{lccc}
\hline Findings & CME (N: 40) & SRD (N: 21) & P value \\
\hline Age (years) & $65.2 \pm 6.3$ & $65.8 \pm 5.6$ & 0.611 \\
Gender (female/male) & $16 / 24$ & $8 / 13$ & 0.887 \\
Duration of BRVO (months) & $4.4 \pm 1.9$ & $4.2 \pm 2.2$ & 0.684 \\
Hypertension & 28 & 15 & 0.885 \\
\hline
\end{tabular}

$\mathrm{BRVO}=$ branch retinal vein occlusion; $\mathrm{CME}=$ cystoid macular edema; $\mathrm{SRD}=$ serous retinal detachment. protocols. Scans with a signal strength of $\geq 7$ were used for analysis. Retinal thickness was defined as the distance between the inner retinal surface of the neurosensory retina and the retinal pigment epithelium. Best-corrected VA was measured using a Snellen Chart and then converted into a logarithm of the minimum angle of resolution (logMAR) for statistical comparison.

Statistical analysis was performed with Python version 2.7.6 and scipy library version 0.13 .3 . The results are presented as the mean \pm standard deviation. Welch's test was used to compare normally distributed unpaired continuous variables between groups. Two-tailed P-values of less than 0.05 were considered statistically significant.

\section{RESULTS}

The characteristics of the CME and SRD groups are summarized in table 1. Of the 61 patients with BRVO, 40 were assigned to the CME group and 21 to the SRD group. All 21 patients in the SRD group had both SRD and CME.

No differences in mean age, female/male ratio, duration of BRVO, and prevalence of hypertension were observed between the CME and SRD groups ( $P=0.611, P=0.887, P=0.684$, and $P=0.885$, respectively; Table 1).

VA was significantly worse in the SRD group compared with the CME (non-SRD) group $(0.82 \pm 0.34$ logMAR vs $0.64 \pm 0.38$ logMAR, $\mathrm{P}=0.005)$. Conversely, CMT was significantly greater in the SRD group than in the CME group ( $465 \pm 115 \mu$ vs $387 \pm 85 \mu, P=0.00004$; Figure 1).

\section{DISCUSSION}

This retrospective study evaluated the relationship between the presence of SRD and VA and CMT in BRVO patients with macular edema. Although SRD is a common feature on OCT images, there is a lack of data regarding the influence of SRD on VA, CMT, and response to therapies in BRVO patients. In the present study, 21 of 61 eyes (34\%) with macular edema secondary to BRVO demonstrated retinal swelling with SRD. Additionally, all SRD patients also had CME. Eyes with SRD had greater foveal thickness with CME. We also observed significantly lower mean VA (logMAR) in the SRD group compared to the CME group, corroborating previous reports ${ }^{(10-13)}$.

Macular edema is the leading cause of visual impairment in BRVO and may be accompanied by various morphological changes. The application of OCT imaging has provided qualitative analysis of the
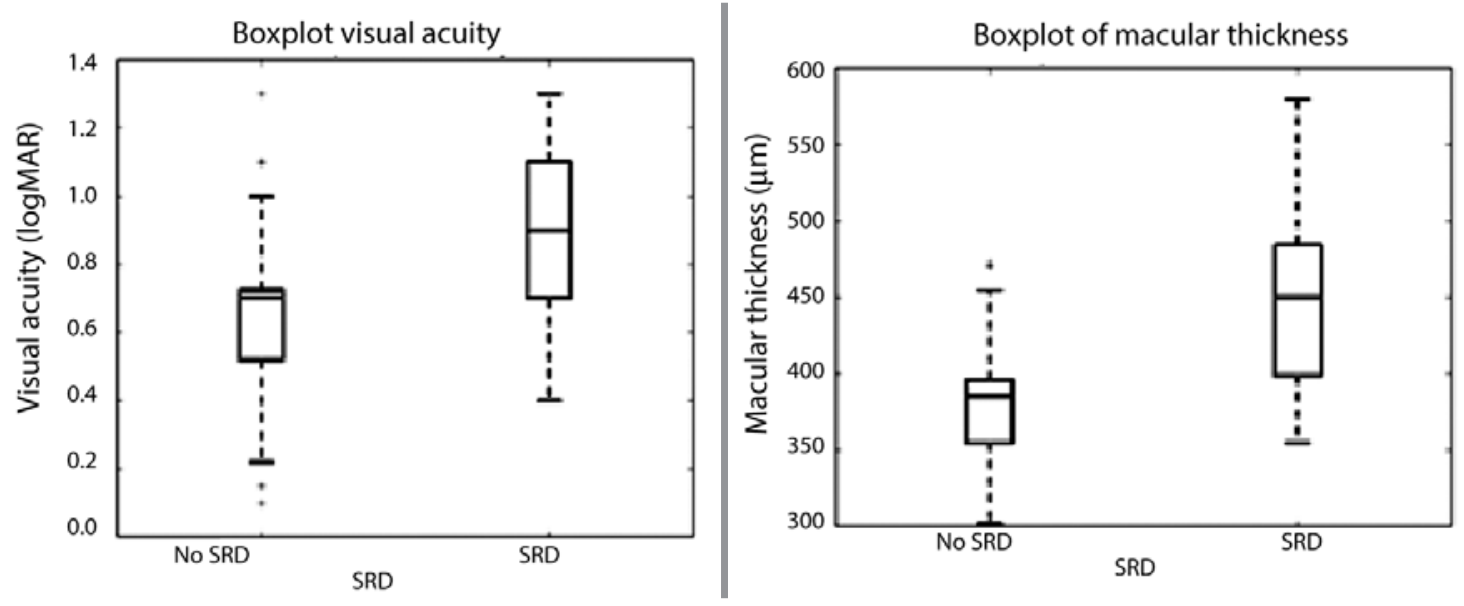

$\mathrm{VA}=$ visual acuity $; \mathrm{CMT}=$ central macular thickness, $\mathrm{SRD}=$ serous retinal detachment; $\mathrm{CME}=$ cystoid macular edema

Figure 1.VA and CMT in the SRD and CME (non-SRD) groups. VA was significantly worse in the SRD group compared with the CME (non-SRD) group. CMT was significantly greater in the SRD group than in the CME group. 
different retinal layers ${ }^{(14)}$. The morphological diversity of the retinal changes associated with macular edema include sponge-like retinal swelling, cystic changes, and SRD ${ }^{(15)}$. Retinal swelling and CME are typically caused by leakage from retinal vessels observed as retinal thickening and oval hyporeflective areas with intraretinal cystoid spaces on OCT. In SRD, fluid accumulates between the neurosensory retina and the RPE, seen as hyporeflective spaces on OCT $T^{(14,15)}$.

A variety of mechanisms have posited to underlie the pathogenesis of SRD. It was previously thought that SRD was associated with hemodynamic overload and disrupted function of the retinal pigment epithelium due to retinal ischemia ${ }^{(16)}$. Marmor and Murakami speculated that vitreal hyperosmolarity may be a possible mechanism underlying the development SRD by allowing the flow of fluid from the vitreous to the choroid ${ }^{(17,18)}$. Ota suggested that small breaks on the external surface of the neurosensory retina, which connects the swollen outer retina, may also be responsible for $\mathrm{SRD}^{(7)}$. In the present study, we performed a detailed analysis of the macula and inner/outer segment of photoreceptors by OCT and found no defects on the external surface of the retina above the site of SRD in any of the evaluated eyes.

The inner half of the fovea includes an inverted cone-shaped zone of Müller cells (the Müller cell cone), the apex of which is located at the external limiting membrane (ELM) of the fovea centralis. The cytoplasm of cells in the Müller cell cone extends obliquely outward and forms the internal limiting membrane at the clivus of the foveal depression ${ }^{(19,20)}$. In eyes with BRVO, leakage from the affected retinal capillaries accumulates around the fovea and causes retinal thickening, which may cause the internal limiting membrane at the clivus of the fovea to protrude, leading to the development of $\mathrm{CME}^{(15)}$. In this case, the cytoplasm of the Müller cell cone extends perpendicularly in the walls of the foveal cystoid spaces. When leakage increases, further traction on the Müller cell cone leads to traction on the inner and outer segments of the foveal photoreceptors resulting in a small area of retinal detachment at the fovea. Subsequently, SRD occurs when the ELM barrier breaks down at the fovea ${ }^{(15)}$. Loss of the ELM barrier often results in damage to foveal photoreceptors in the outer segment and VA impairment ${ }^{(10)}$. Thus, the mean VA of the SRD group may have been significantly worse as a result of damage to foveal photoreceptor cells due to foveal detachment. In addition, all SRD patients in the present study also had CME. Therefore, we believe SRD itself may decrease VA.

In the present study, we observed greater CMT in the SRD group compared to the CME group, corroborating previous reports. In BRVO patients, SRD occurs as a result of transudation of extracellular fluid into the subretinal space with the site of detachment being determined by foveal architecture, particularly the presence of the Müller cell cone ${ }^{(21,22)}$. Furthermore, when the barrier function of the ELM breaks down due to traction on the Müller cell cone, intraretinal fluid moves into the subretinal space resulting in an increase of SRD and alleviation of retinal edema ${ }^{(12,15)}$. This process may have contributed to the greater CMT in the SRD group compared to the CME group.

Inflammatory factors may be strongly associated with the occurrence of SRD in BRVO patients. Noma et al. ${ }^{(23)}$ reported that vitreous fluid levels of VEGF and sICAM-1, potent vasopermeability factors, were higher in BRVO patients with SRD compared to those with CME. They also reported significantly worse VA in the SRD group compared with the CME group and significantly greater CMT in the SRD group. They proposed that worse VA in the SRD group may be related to photoreceptor cell damage caused by macular detachment and/or functional impairment secondary to ischemia with high vitreous fluid levels of VEGF and ICAM-1 ${ }^{(23)}$. In another study evaluating the efficacy of intravitreal triamcinolone acetonide for CME with SRD in BRVO, triamcinolone acetonide was thought to reduce CMT by decreasing retinal capillary permeability via an effect on tight junctions and/or inhibition of signaling cascades involving VEGF and the VEGF receptor ${ }^{(13)}$. Moreover, decreased retinal capillary permeability may relieve traction on the Muller cell cone resulting in decreased SRD. Corticosteroids may also prevent the production of various inflammatory molecules that promote leukocyte adhesion and breakdown of the blood-retinal barrier ${ }^{(13)}$.

The limitations of the present study were its retrospective nature, small sample size, lack of functional mapping by microperimetry (macular sensitivity), and lack of BRVO patients with SRD only.

In conclusion, the mean VA was significantly worse in the SRD group compared with the CME group, and eyes with SRD had greater CMT. We observed that SRD itself may be related to decreased VA. Further detailed studies with a larger number of patients are required to confirm the role of SRD as a predictive factor of VA and prognosis.

\section{REFERENCES}

1. Orth DH, Patz A. Retinal branch vein occlusion. Surv Ophthalmol. 1978;22(6):357-76.

2. Hayreh SS. Retinal vein occlusion. Indian J Ophthalmol. 1994;42(3):109-32.

3. Rehak M, Wiedemann P. Retinal vein thrombosis: pathogenesis and management. J Thromb Haemost. 2010;8(9):1886-94.

4. Rehak J, Rehak M. Branch retinal vein occlusion: pathogenesis, visual prognosis, and treatment modalities. Curr Eye Res. 2008:33(2):111-31.

5. Karia N. Retinal vein occlusion: pathophysiology and treatment options. Clin Ophthalmol. 2010:30(4):809-16.

6. Keane PA, Sadda SR. Predicting visual outcomes for macular disease using optical coherence tomography. Saudi J Ophthalmol. 2011;25(2):145-58.

7. Ota T, Tsujikawa A, Murakami T, Ogino K, Muraoka Y, Kumagai K, et al. Subfoveal serous retinal detachment associated with extramacular branch retinal vein occlusion. Clin Ophthalmol. 2013:7:237-41.

8. Sekiryu T, lida T, Sakai E, Maruko I, Ojima A, Sugano Y. Fundus autofluorescence and optical coherence tomography findings in branch retinal vein occlusion. J Ophthalmol. 2012:2012:638064.

9. Otani T, Yamaguchi Y, Kishi S. Movement of intraretinal fluid from distant branch retinal vein occlusion to the submacular space. Clin Ophthalmol. 2013;7:81-6.

10. Noma H, Funatsu H, Mimura T, Shimada K. Visual function and serous retinal detachment in patients with branch retinal vein occlusion and macular edema: acase series. BMC Ophthalmol. 2011:11:29.

11. Karacorlu M, Ozdemir H, Karacorlu SA. Resolution of serous macular detachment after intravitreal triamcinolone acetonide treatment of patients with branch retinal vein occlusion. Retina. 2005;25(7):856-60

12. Tsujikawa A, Sakamoto A, Ota M, Kotera Y, Oh H, Miyamoto K, et al. Serous retinal detachment associated with retinal vein occlusion. Am J Ophthalmol. 2010;149(2):291-301.

13. Noma H, Funatsu H, Mimura T, Shimada K. Comparison of the efficacy of intravitreal triamcinolone acetonide for cystoid macular edema with versus without serous retinal detachment in branch retinal vein occlusion: influence on macular sensitivity and morphology. BMC Ophthalmol. 2012;12(39):1-10.

14. Otani T, Kishi S. Correlation between optical coherence tomography and fluorescein angiography findings in diabetic macular edema. Ophthalmology. 2007;114(1):104-7.

15. Spaide RF, Lee JK, Klancnik JK Jr, Gross NE. Optical coherence tomography of branch retinal vein occlusion. Retina. 2003;23(3):343-7.

16. Battaglia Parodi M, Isola V. Branch retinal vein occlusion and exudative retinal detachment: pathogenetical aspects. Ophthalmologica. 1994;208(1):29-31.

17. Marmor MF. Control of subretinal fluid: experimental and clinical studies. Eye (Lond). 1990;4(Part 2):340-4.

18. Murakami T, Tsujikawa A, Miyamoto K, Sakamoto A, Ota M, Ogino K, et al. Relationship between perifoveal capillaries and pathomorphology in macular oedema associated with branch retinal vein occlusion. Eye (Lond). 2012;26(6):771-80.

19. Yamada E. Some structural features of the fovea centralis in the human retina. Arch Ophthalmol. 1969:82(2):151-9.

20. Gass JD. Muller cell cone, an overlooked part of the anatomy of the fovea centralis: hypotheses concerning its role in the pathogenesis of macular hole and foveomacular retinoschisis. Arch Ophthalmol. 1999;117(6):821-3.

21. YamaguchiY, Otani T, Kishi S. Serous macular detachment in branch retinal vein occlusion. Retina. 2006;26(9):1029-33

22. Shroff D, Mehta DK, Arora R, Narula R, Chauhan D. Natural history of macular status in recent-onset branch retinal vein occlusion: an optical coherence tomography study. Int Ophthalmol. 2008;28(4):261-8.

23. Noma H, Funatsu H, Miura T, Tatsugawa M, Shimada K, Eguchi S. Vitreous inflammatory factors and serous macular detachment in branch retinal vein occlusion. Retina. 2012; 32(1):86-91. 